\title{
Sublingual Misoprostol Versus Manual Vacuum Aspiration for Treatment of Incomplete Abortion in Nigeria: A Randomized Control Study
}

\section{Vincent Chinedu Ani}

Nnamdi Azikiwe University Teaching Hospital

\section{Enebe J. Tochukwu}

Enugu State University of Science and Technology College of Medicine https://orcid.org/0000-00023517-1104

Cyril Chukwudi Dim ( $\nabla$ cyril.dim@unn.edu.ng)

University of Nigeria Ituku-Ozalla Campus https://orcid.org/0000-0003-3469-3549

\section{Ngozi Regina Dim}

University of Nigeria Teaching Hospital

\section{Benjamin Chukwuma Ozumba}

University of Nigeria Faculty of Medical Sciences

\section{Research article}

Keywords: Sublingual misoprostol, Post-abortion care, Complete abortion, Manual vacuum aspiration, South-east Nigeria.

Posted Date: October 9th, 2020

DOl: https://doi.org/10.21203/rs.3.rs-72124/v1

License: @ (i) This work is licensed under a Creative Commons Attribution 4.0 International License. Read Full License

Version of Record: A version of this preprint was published at Pan African Medical Journal on January 1st, 2022. See the published version at https://doi.org/10.11604/pamj.2022.41.90.29364. 


\section{Abstract}

Objectives: To compare the effectiveness of single-dose sublingual misoprostol to manual vacuum aspiration in the treatment of incomplete spontaneous abortion in Enugu, Nigeria.

Design: Multi-centre randomized controlled trial

Setting: A teaching hospital, the University of Nigeria Teaching Hospital (UNTH) Ituku-Ozalla, Enugu and a private specialist hospital, Julius Memorial Specialist Hospital Enugu, Nigeria were used for the study

Participants: In all, 212 consecutive consenting women with sonologically confirmed, first-trimester incomplete spontaneous abortion at the gynaecological emergency departments of the study centers were recruited but, 203 women completed the study and their results analysed.

Intervention: Single-dose of sublingual misoprostol $400 \mathrm{mcg}$ with the participant followed-up at the gynecology clinic one week after with an ultrasound scan for the completeness of the uterine evacuation.

Main outcomes measures: The primary outcome measure was the incidence of complete uterine evacuation (complete abortion) after one week of treatment while the secondary outcome measures included incidence, types, and tolerability of treatment side effects as well as participants' satisfaction with the treatment received

Results: Two hundred and three eligible women were randomised into the intervention group $(n=102)$ that received single-dose sublingual misoprostol $400 \mathrm{mcg}$ and the control group $(n=101)$ that received manual vacuum aspiration. Incidence of complete abortion was $86.3 \%$ for the misoprostol group and $100.0 \%$ for the control group, $R R=0.86,(\mathrm{Cl} 95 \%: 0.80-0.93), p<0.001$. The most common side effect was abdominal pain with an incidence of $27.5 \%$ versus 48.55 for the misoprostol and control groups respectively $(p=0.002)$. Most participants in each group $(81.1 \%$ versus $77.6 \%$ for the misoprostol and control groups respectively) considered the side effects as tolerable. The mean visual analogue scale score for maternal satisfaction was higher in the misoprostol group $(86.7 \pm 14.11)$ than the control group (81.36 \pm 11.10$), p<0.001$.

Conclusions: The treatment of incomplete spontaneous abortion with single-dose sublingual misoprostol $400 \mathrm{mcg}$ produced a high rate of complete abortion among women in Enugu, Nigeria. Despite having a lower complete abortion rate, maternal satisfaction was higher when compared with women that had manual vacuum aspiration of the uterus.

Trial registration: Trial registration number - PACTR202009857889210, date of registration - 23 September 2020. Retrospectively registered

\section{Background}


Abortion which can be spontaneous or induced contributes up to $13.2 \%$ of all maternal deaths globally. [1] It is referred to as incomplete when the products of conception are retained within the uterine cavity and may lead to complications such as hemorrhage, infection, renal failure, and death. These products of conception can be detected on ultrasound examination. It has been established that abortion-related death is especially prevalent in low resource settings, wherever abortion laws are restrictive or when access to safe abortion services is difficult. [2] For instance, in Nigeria, the Federal Ministry of Health ( $\mathrm{FMoH})$ attributes $11 \%$ of maternal deaths to complications of abortion. [3] Therefore, to address complications related to unsafe abortion, post-abortion care (PAC) was introduced for use in the management of incomplete abortion. This involves treating the affected women with empathy, uterine evacuation if incomplete, the use of antibiotics, and contraception among other components. [4] Originally, evacuation of the uterus in PAC focused on suction evacuation with high patronage of manual vacuum aspiration (MVA) in resource-poor settings. However, though MVA is a safe and effective treatment option for early pregnancy loss,[5] its accessibility in low resource countries is constrained by the unavailability of sterile equipment and skilled provider generally,[6] as well as other challenges such as the need for theatre space, cost of the procedure, and peculiar complications including cervical trauma and uterine perforation. Because of these constraints, there was a need to explore effective, accessible, \& acceptable non-surgical options.

There is increasing evidence that misoprostol, a prostaglandin E2 analogue, is a safe, effective, and acceptable method to achieve uterine evacuation for women in need of PAC services because it does not require the immediate availability of sterilized equipment, operating theatres or skilled personnel. [7] These features among others render misoprostol an important alternative to PAC with MVA particularly in low resource and remote areas. [8] Misoprostol can be administered through several routes in obstetrics and gynecological practice, however, for medical management of incomplete abortion, a single oral dose $600 \mathrm{mcg}$ is recommended. [9] Very important to our resource-poor setting with the attendant underdeveloped health insurance system is the fact that misoprostol reduces the cost of post-abortion care services substantially by removing the need for theater space, sterile instruments, skilled personnel, and their associated financial implications. These advantages will be further enhanced by the identification of a more convenient route(s) of administration that allows a lower dose of misoprostol. Single-dose misoprostol $400 \mathrm{mcg}$ administered through the sublingual route appears to offer these enhanced advantages. [10] This route of administration and dosage are also associated with high levels of satisfaction and acceptability to patients involved. [11]

In our setting, services and training on post-abortion care often focus on the use of MVA for uterine evacuation, [12] which calls for the scale-up of PAC services to include the use of misoprostol by the most convenient route and most effective small dose. This study, therefore, compared the efficacy of singledose sublingual misoprostol $400 \mathrm{mcg}$ to manual vacuum aspiration for the complete evacuation of the uterus in cases of incomplete abortion in Enugu, South-east Nigeria. This study adhered to CONSORT guidelines in the reporting of the research findings. 


\section{Methods}

\section{Study design/study setting}

This study was an open-labeled randomized controlled study of 203 consenting women with incomplete abortion who presented at the gynecological emergency unit of the University of Nigeria Teaching Hospital (UNTH) Ituku- Ozalla, Enugu and Julius Memorial Specialist Hospital Enugu, Nigeria. The UNTH is a teaching hospital that offers 24-hour emergency obstetrics care as part of its comprehensive multispecialist emergency services. Julius Memorial Specialist Hospital is a private specialist hospital situated in Abakpa Nike - a suburb and the most densely inhabited part of Enugu metropolis. It runs a 24-hour comprehensive emergency obstetric care and serves as a referral center for maternity homes and health centers in Enugu East local government area of Enugu State, Nigeria. Enugu is the capital city of Enugu state which is in the South-eastern geopolitical zone of Nigeria.

\section{Sample recruitment}

All consenting women at the study centers with first-trimester incomplete abortion, confirmed by a transabdominal ultrasound scan of the uterus, were eligible for the study. Women with excessive vaginal bleeding, severe anemia $(\mathrm{Hb}<7.0 \mathrm{~g} \%)$, or suspected ectopic pregnancy were excluded from the study. Other exclusion criteria were a history of allergy to prostaglandins, evidence of genital infection such as offensive vaginal discharge, uterine tenderness, and pyrexia.

As illustrated in Figure 1, 212 consecutive consenting eligible women were randomized into two treatment groups; intervention group $A(n=110)$ received single-dose sublingual misoprostol $400 \mathrm{mcg}$ while the control group B ( $n=102)$ had immediate manual vacuum aspiration (MVA) of the uterus. Participants' randomization was by simple random allocation - after obtaining informed consent, each participant was assigned a sequential number ( 1 to 212 ) then, she picked one of the two balls (same size and texture) from a black bag. Each ball was marked A or B representing the two treatment groups. The participant was allocated to the treatment group written on the ball she picked. The sample size on each arm was adequate to identify a $95.5 \%$ difference in the incidence of complete uterine evacuation between the two treatment groups, based on the assumed incidence of complete abortion of $90 \%$ for the MVA $\left(p_{0}\right)$, power of $80 \%$, alpha of 0.05 , and attrition rate of $10 \%$.

\section{Data collection method}

Each participant in the misoprostol group was given $400 \mathrm{mcg}$ of misoprostol (Cytotec $®$ ) placed under their tongues for 30 minutes to enable the tablets to dissolve. They were observed for about 8 hours after the drug administration and allowed home. Each participant was given the mobile phone number of the principal investigator for the reporting of any side effects or complications. They were discharged on analgesics - oral ibuprofen $400 \mathrm{mg}$ twelve hourly for 5 days, and prophylactic antibiotics - oral amoxicillin/clavulanic acid $625 \mathrm{mg} 8$ hourly, and metronidazole $400 \mathrm{mg} 8$ hourly for 1 week. Follow-up at the gynecology clinic visit was scheduled for each participant after one week. During the follow-up visit, 
they were clinically and sonologically evaluated for complete abortion; according to the study protocol, those with incomplete uterine evacuation were offered immediate manual vacuum aspiration or further observation for an extra week after which surgical evacuation would be carried out if the uterine cavity was not empty.

Participants in the MVA group (B) were offered immediate manual vacuum aspiration in the theater by trained medical practitioners, using standard procedure. [13] After the procedure, each was observed for 2 hours then, discharged home on the analgesics and prophylactic antibiotics described above. Each was scheduled for a follow-up clinic visit after 1 week of treatment, during which they were evaluated by ultrasound scan for complete uterine evacuation. In the case of incomplete uterine evacuation, the protocol was a repeat uterine evacuation by MVA.

At the initial treatment visit, participants' baseline data on socio-demographics, gestational age, contraceptive history, and assigned treatment groups were documented. Their mobile phone numbers or that of a close relative was obtained. During the follow-up visit, information on the completeness of the uterine evacuation, treatment side effects and their severity, and satisfaction with treatment were obtained and recorded on the study's datasheet for all participants. All documentations were made by the principal investigator and his trained assistants. Participant's perceived severity of side-effect was assessed with a three-point Likert scale (i.e. mild/tolerable, moderate/less tolerable, and severe/intolerable). Also, the participants' satisfaction with the treatment received was assessed using the visual analogue scale (VAS) (0 - 100), as described by Mba et.al.[14] All participants were also offered post-abortion contraceptive counseling and service and linked to other reproductive health services as appropriate. For the study, incomplete abortion was diagnosed when a pregnant woman presented with a history of vaginal bleeding with dilated cervix on physical examination as well as abdominopelvic ultrasound scan features of a retained product of conception.

\section{Data variable}

The primary outcome measure was the incidence of complete uterine evacuation (complete abortion) after one week of treatment with single-dose sublingual misoprostol $400 \mathrm{mcg}$ or MVA. The secondary outcome measures included incidence, types, and tolerability of treatment side effects as well as participants' satisfaction with the treatment received.

\section{Ethical approval}

The study was approved by the Human Research Ethics Committee of the University of Nigeria Teaching Hospital, Enugu, Nigeria.

\section{Data analysis}

Data for 102 and 101 women were analyzed in the intervention (misoprostol) and control (MVA) groups respectively (figure 1) using the statistical package for social sciences (SPSS) computer software, version 20.0 for Windows (IBM Corporation). Data analysis was per protocol. Continuous variables were 
compared using the student's t-test while the discrete variables were analyzed using proportions, and their associations compared with Pearson's chi-square or Fisher's exact where applicable. A probability value of less than 0.05 was considered statistically significant.

\section{Results}

Out of a total of 227 participants assessed for eligibility, 212 participants met the study criteria. At randomization 110 received the intervention while 102 were in the control group. A total of eight and one participants in the intervention and control groups respectively were lost to follow up. Therefore, a total of 203 participants who met the study criteria and completed the study from August 2014 to February 2015 were randomised into the intervention group $(n=102)$ that received single-dose sublingual misoprostol $400 \mathrm{mcg}$ and the control group $(n=101)$ that received manual vacuum aspiration. Details are shown in figure 1.

Participants' basic characteristics (Table 1) were similar between the two groups. The mean ages of the participants were $28.7 \pm 5.83$ versus $29.0 \pm 6.49$ years for the misoprostol and MVA groups respectively $(p=0.795)$. Likewise, the mean gestational age at presentation was $9.1 \pm 2.0$ weeks for the misoprostol group and $9.1 \pm 2.1$ weeks for the MVA group $(p=0.975)$.

The incidence of complete uterine evacuation after 7 days of follow-up was $86.3 \%$ (88/102) for the misoprostol group and $100.0 \%(101 / 101)$ for the MVA group. The observed difference was statistically significant $\mathrm{RR}=0.86,(\mathrm{Cl} 95 \%$ : 0.80 - 0.93), $\mathrm{p}<0.001$. All women with incomplete uterine evacuation after 7 days of treatment in the misoprostol group (14/102, 13.7\%), opted for MVA of the uterus rather than an extra week follow-up for the misoprostol effect.

Details of the types and distribution of side effects among study participants are shown in table 2 . Treatment side effects were commoner in the misoprostol group (88.2\% (90/102) compared to the MVA group (57.4\%, 58/101), RR = 1.5, $(\mathrm{Cl} 95 \%: 1.28,1.84), \mathrm{p}<0.001$. The most common side effect was abdominal pain which had an incidence of $27.5 \%(28 / 102)$ in the misoprostol group versus $48.5 \%$ (49/101) in the MVA group, $R R=0.6,(C l 95 \%: 0.39-0.82), p=0.002$. As shown in table 3 , most participants with side effects in both groups considered them as mild and tolerable - misoprostol group $(81.1 \%, 73 / 90)$ versus (77.6\% 45/58), R.R = 1.1 (Cl95\%: $0.88-1.24), p=0.677$.

As regards to maternal satisfaction for the treatment received, the mean VAS scores for the misoprostol group $(86.7 \pm 14.11)$ was significantly higher than that of the MVA group $(81.36 \pm 11.10), p<0.001$. Eighty (88.9\%) participants in the misoprostol group would recommend the treatment to other women with incomplete abortion in the first trimester while $63(62.4 \%)$ women in the control group would recommend MVA to women in a similar situation, $R R=1.3,(C l 95 \%: 1.05-1.51), p=0.014$.

\section{Discussion}


It is recognized that about $10-15 \%$ of all pregnancies end in spontaneous abortion, [15] and another proportion is willfully terminated due to unintended pregnancy; for instance, rates of 33 to 46 induced abortions per 1,000 women of reproductive age group were reported in Nigeria. $[16,17]$ It is noteworthy that either of these categories can end in incomplete abortion with the attendant morbidities and mortality when not managed appropriately. Thus, the need for a more convenient, affordable, and nonsurgical treatment method in our environment cannot be over-emphasized.

This study has shown that treatment of incomplete abortion with a single dose sublingual misoprostol $400 \mathrm{mcg}$ followed up for 1 week was effective for the complete abortion though, it was about $14 \%$ less effective than immediate uterine evacuation with MVA. The finding in the misoprostol group of this study is similar to $88.4 \%$ reported in Ibadan Nigeria, [6], and 86.9\% in Burkina Faso [18]. However, it is lower than 91.8\% reported in a multi-country study from sub-Saharan Africa, [10] 98.3\% in Egypt, [11], and 99.4\% in Senegal. [19] All these related studies reviewed the misoprostol treatment success rate after 7 days' follow-up of participants. As demonstrated in earlier studies, $[6,18]$ a follow-up of participants for two weeks after misoprostol administration yields higher uterine complete evacuation rate of up to $98.0 \%$, [18] which is comparable to the MVA evacuation rate in this study and other studies. $[10,11,20]$ This might explain the recommendation that women being treated with misoprostol as part of post-abortion care should be followed-up for 1 to 2 weeks to ensure complete abortion. [2] Unfortunately, this study has no data for 2 weeks follow-up because participants in the misoprostol group with incomplete evacuation after 1 week of treatment, did not consent to an extra week of follow-up.

The study found that the treatment side effects were commoner in the misoprostol group but, fortunately, over $80 \%$ of the complaints were mild in severity which might explain the lack of difference in the side effect tolerability by participants in the two treatment groups. Previous studies had also found no difference in the tolerability of side effects between the two treatment groups. [10, 11] Misoprostol for uterine evacuation works through its uterotonic property so, a higher incidence of abdominal pain, as a side effect, is expected among participants in that group, $[10,11]$ but, that was not the case in this study for reasons that are not clear. A related study of a similar population in Nigeria observed more abdominal pain in the misoprostol group (single-dose oral misoprostol $600 \mathrm{mcg}$ ) when compared to the MVA group, [21] which might rule-out population peculiarities as a possible reason for this unusual finding. Though a report from Madagascar found no difference in the mean abdominal pain score between cohorts of women that used oral $(600 \mathrm{mcg})$ versus sublingual $(400 \mathrm{mcg})$ misoprostol for incomplete miscarriage treatment, [22] it is important to explore in subsequent studies whether the sublingual route of misoprostol is associated with less abdominal pain in our environment.

Misoprostol treatment was highly acceptable to participants in this study when compared to the MVA considering that they were more likely to recommend the treatment to other women with incomplete miscarriage when compared to women that had MVA. This high acceptance was also expressed in related studies. $[6,10,18]$ This study did not seek reasons for this high acceptability but, it was likely to border on the fact that the treatment did not involve the use of surgery so, it was viewed as more convenient and cheaper. It has been established that women from the study environment have a strong 
aversion for cesarean sections, $[23,24]$ and it may not be out of place to believe that this aversion extends to other pregnancy-related surgeries including MVA. Future studies in this subject should specifically seek for reason for the preference/non-preference of each treatment method.

The nature of the study made blinding of both investigators and participants difficult but, the lack of blinding could not have impacted the study's estimates. Discontinuation rate when assessed as an outcome measure might reflect adverse events; [25] it is, therefore, likely that the larger loss to follow-up in the misoprostol group might be related to severe treatment side effect; however, further data analysis showed that this scenario did not affect the treatment tolerability in both groups. The study remains relevant in Nigeria and similar under-resourced settings because it has added strong evidence for the use of a lower and cheaper dose of misoprostol through a convenient route, for the treatment of incomplete abortion.

\section{Conclusions}

This study has shown that the use of single-dose sublingual misoprostol $400 \mathrm{mcg}$ followed up for 1 week, for the treatment of incomplete abortion produced a high rate of complete abortion though, it was less effective than surgical evacuation by manual vacuum aspiration. Also, women that received single-dose sublingual misoprostol $400 \mathrm{mcg}$ had a higher incidence of side effects when compared to the MVA group but, the majority of the side effects were mild and tolerable. Finally, when compared to women that received MVA, women treated with misoprostol were more satisfied with their treatment and were more likely to recommend the treatment to others with incomplete first-trimester abortion. It is therefore recommended that the single-dose misoprostol $400 \mathrm{mcg}$ should be included as a treatment option for the post-abortion care of eligible women with first-trimester incomplete abortion in the study environment.

\section{List Of Abbreviations}

FMoH - Federal Ministry of Health

MVA - manual vacuum aspiration

PAC - post-abortion care

SPSS - statistical package for social sciences

UNTH - University of Nigeria Teaching Hospital

VAS: Visual analogue scale

\section{Declarations}

Ethical approval and consent to participate: The ethical clearance certificate number NHREC/05/01/2008B - FWA00002458 - IRB 00002323 for this research was obtained from Research 
and Ethics Committee of University of Nigeria Teaching Hospital Ituku/ Ozalla, Enugu. A written informed consent was obtained from each participant before they were recruited into the study.

Consent for publication: Not applicable

Availability of data and materials: The data sets used and/or analysed during the current study are available from the corresponding author on reasonable request

Competing interests: The authors declare no conflict of interest.

The abstract of this manuscript was presented at the Global Maternal Newborn Health Conference held from $18-21^{\text {st }}$ October 2015, Mexico City, Mexico

Funding: There was no funding from any organization for this research work. This research was completely sponsored/funded by the authors.

Authors' contributions: VC and CC contributed significantly in the conception, designing, data collection, analysis, and final draft of the manuscript. JT and NR were involved in the conception, data collection, analysis and final draft of the manuscript. BC made significant contributions to the conception, designing, analysis, and writing of the final draft of the manuscript. All authors read and approved the final manuscript.

\section{Acknowledgments}

We acknowledge the study's research assistants, Drs Ugochukwu Ezenyirioha, Ifeanyi Ononuju, Okechukwu Ifebi.

\section{References}

1. Say L, Chou D, Gemmill A, Tuncalp O, Moller A-B, Daniels J, et al. Global causes of maternal death: a WHO systematic analysis. Lancet Glob Health. 2014;2(6):e323-e33.

2. American College of O, Gynecologists. ACOG Committee Opinion No. 427: Misoprostol for postabortion care. Obstet Gynecol. 2009;113(2 Pt 1):465-8.

3. Federal Ministry of Health (FMoH) Nigeria. Integrated Maternal, Newborn and Child Health Strategy. Abuja: $\mathrm{FMoH} ; 2007$.

4. Greenslade FC, McKay H, Wolf M, McLaurin K. Post-abortion care: a women's health initiative to combat unsafe abortion. Adv Abort Care. 1994;4(1):1-4.

5. Hemlin J, Moller B. Manual vacuum aspiration, a safe and effective alternative in early pregnancy termination. Acta Obstet Gynecol Scand. 2001;80(6):563-7.

6. Fawole AO, Diop A, Adeyanju AO, Aremu OT, Winikoff B. Misoprostol as first-line treatment for incomplete abortion at a secondary-level health facility in Nigeria. Int J Gynaecol Obstet. 2012;119(2):170-3. 
7. You JHS, Chung TKH. Expectant, medical or surgical treatment for spontaneous abortion in first trimester of pregnancy: a cost analysis. Hum Reprod. 2005;20(10):2873-8.

8. Dah T, Akiode A, Awah P, Fetters T, Okoh M, Ujah I, et al. Introducing misoprostol for the treatment of incomplete abortion in Nigeria. Afr J Reprod Health. 2011;15(4):42-50.

9. Blum J, Winikoff B, Gemzell-Danielsson K, Ho PC, Schiavon R, Weeks A. Treatment of incomplete abortion and miscarriage with misoprostol. Int J Gynaecol Obstet. 2007;99 Suppl 2:S186-S9.

10. Shochet T, Diop A, Gaye A, Nayama M, Sall AB, Bukola F, et al. Sublingual misoprostol versus standard surgical care for treatment of incomplete abortion in five sub-Saharan African countries. BMC Pregnancy Childbirth. 2012;12:127-.

11. Dabash R, Ramadan MC, Darwish E, Hassanein N, Blum J, Winikoff B. A randomized controlled trial of $400-\mu \mathrm{g}$ sublingual misoprostol versus manual vacuum aspiration for the treatment of incomplete abortion in two Egyptian hospitals. Int J Gynaecol Obstet. 2010;111(2):131-5.

12. Akaba GO, Abdullahi HI, Atterwahmie AA, Uche Ul. Misoprostol for treatment of incomplete abortions by gynecologists in Nigeria: A cross-sectional study. Nigerian Journal of Basic and Clinical Sciences. 2019;16(2):90.

13. Frankel N. Performing uterine evacuation with the Ipas MVA Plus ${ }^{\circledR}$ aspirator and Ipas EasyGrip ${ }^{\circledR}$ cannulae: instructional CD-ROM. Chapel Hill (NC): Ipas. 2004.

14. Mba SG, Dim CC, Onah HE, Ezegwui HU, lyoke CA. Effects of early oral feeding versus delayed feeding on gastrointestinal function of post-caesarean section women in a tertiary hospital in Enugu, Nigeria: A randomized controlled trial. Niger J Clin Pract. 2019;22(7):943-9.

15. Kim C, Barnard S, Neilson JP, Hickey M, Vazquez JC, Dou L. Medical treatments for incomplete miscarriage. Cochrane Database of Systematic Reviews. 2017 (1).

16. Bankole A, Adewole IF, Hussain R, Awolude O, Singh S, Akinyemi JO. The Incidence of Abortion in Nigeria. International perspectives on sexual and reproductive health. 2015;41(4):170-81.

17. Bell So, Omoluabi E, OlaOlorun F, Shankar M, Moreau C. Inequities in the incidence and safety of abortion in Nigeria. BMJ Glob Health. 2020;5(1):e001814-e.

18. Blandine T, Ouattara AZ, Coral A, Hassane C, Clotaire H, Dao B, et al. Sublingual [corrected] misoprostol as first-line care for incomplete abortion in Burkina Faso. Int J Gynaecol Obstet. 2012;119(2):166-9.

19. Gaye A, Diop A, Shochet T, Winikoff B. Decentralizing postabortion care in Senegal with misoprostol for incomplete abortion. Int J Gynaecol Obstet. 2014;126(3):223-6.

20. Ibiyemi KF, ljaiya MA, Adesina KT. Randomised Trial of Oral Misoprostol Versus Manual Vacuum Aspiration for the Treatment of Incomplete Abortion at a Nigerian Tertiary Hospital. Sultan Qaboos University medical journal. 2019;19(1):e38-e43.

21. Chigbu B, Onwere S, Aluka C, Kamanu C, Ezenobi O. Is Misoprostol A Suitable Alternative To The Surgical Evacuation Of Incomplete Abortion In Rural South-Eastern Nigeria? East African medical journal. 2012;89(5):172-7. 
22. Diop A, Raghavan S, Rakotovao JP, Comendant R, Blumenthal PD, Winikoff B. Two routes of administration for misoprostol in the treatment of incomplete abortion: a randomized clinical trial. Contraception. 2009;79(6):456-62.

23. Chigbu CO, lloabachie GC. The burden of caesarean section refusal in a developing country setting. BJOG : an international journal of obstetrics and gynaecology. 2007;114(10):1261-5.

24. Lawani LO, Igboke FN, Ukaegbe Cl, Anozie OB, lyoke CA, Onu FA, et al. Perception and Socio-cultural Barriers to the Acceptance of Caesarean Delivery in A Tertiary Hospital in Abakaliki, South East Nigeria. IJWHR 2019; 7: 163-168

25. Gartlehner G, Hansen RA, Nissman D, Lohr KN, Carey TS. A simple and valid tool distinguished efficacy from effectiveness studies. Journal of clinical epidemiology. 2006;59(10):1040-8.

\section{Tables}


Table 1

Basic Characteristics of the Study Participants

\begin{tabular}{|c|c|c|c|c|}
\hline \multirow[t]{2}{*}{ Characteristics } & \multirow[t]{2}{*}{ Sub-groups } & $\begin{array}{l}\text { Misoprostol group } \\
(\mathrm{n}=102)\end{array}$ & $\begin{array}{l}\text { MVA group } \\
(n=101)\end{array}$ & \multirow[t]{2}{*}{ P-value } \\
\hline & & Frequency (\%) & Frequency (\%) & \\
\hline \multirow[t]{7}{*}{ Age (years) } & 20 & $1(1.0 \%)$ & $4(4.0 \%)$ & \multirow[t]{6}{*}{0.219} \\
\hline & $20-24$ & $29(28.4 \%)$ & $28(27.7 \%)$ & \\
\hline & $25-29$ & 25 (24.5\%) & 19 (18.8\%) & \\
\hline & $30-34$ & $29(28.4 \%)$ & $32(31.7 \%)$ & \\
\hline & $35-39$ & $14(13.7 \%)$ & $23(11.3 \%)$ & \\
\hline & $40-44$ & $4(3.9 \%)$ & $9(8.9 \%)$ & \\
\hline & Mean \pm SD & $28.7 \pm 5.83$ & $29.0 \pm 6.49$ & 0.795 \\
\hline \multirow[t]{2}{*}{ Marital Status } & Married & $75(48.7 \%)$ & 79 (51.3\%) & \multirow[t]{2}{*}{0.435} \\
\hline & Single & $27(55.1 \%)$ & $22(44.9 \%)$ & \\
\hline \multirow[t]{3}{*}{ Educational status } & Primary & $1(20.0 \%)$ & $4(80.0 \%)$ & \multirow[t]{3}{*}{0.260} \\
\hline & Secondary & $43(47.8 \%)$ & $47(52.2 \%)$ & \\
\hline & Tertiary & $58(53.7 \%)$ & $50(46.3 \%)$ & \\
\hline \multirow[t]{5}{*}{ Parity groups } & 0 & $31(54.4 \%)$ & $26(45.6 \%)$ & \multirow[t]{4}{*}{0.634} \\
\hline & 1 & $14(43.8 \%)$ & $18(56.2 \%)$ & \\
\hline & $2-4$ & $52(51.5 \%)$ & $49(48.5 \%)$ & \\
\hline & $\geq 5$ & $5(38.5 \%)$ & $8(61.5 \%)$ & \\
\hline & Mean \pm SD & $1.8 \pm 1.53$ & $2.0 \pm 1.78$ & 0.378 \\
\hline
\end{tabular}


Table 2

Side Effects Distribution by Treatment Groups

\begin{tabular}{|lllll|}
\hline Side effect & $\begin{array}{l}\text { Misoprostol } \\
(\mathbf{n = 1 0 2})\end{array}$ & $\begin{array}{l}\text { MVA } \\
(\mathbf{n = 1 0 1 )}\end{array}$ & P value & RR (Cl 95\%) \\
\cline { 2 - 4 } & Freq (\%) & Freq (\%) & & \\
\hline Abdominal pain & $28(27.5)$ & $49(48.5)$ & 0.002 & $0.6(0.39,0.82)$ \\
\hline Nausea & $16(15.7)$ & $1(1.0)$ & $<0.001$ & $15.8(2.14,117.24)$ \\
\hline Vomiting & $18(17.7)$ & $3(3.0)$ & $<0.001$ & $5.9(1.81,19.55)$ \\
\hline Diarrhoea & $10(9.8)$ & $0(0.0)$ & $<0.001$ & - \\
\hline Bleeding & $6(5.9)$ & $1(1.0)$ & 0.119 & $6.0(0.73,48.47)$ \\
\hline Chills & $12(11.8)$ & $4(4.0)$ & 0.654 & $3.0(0.99,8.90)$ \\
\hline All side effects & $90(88.2)$ & $58(57.4)$ & $<0.001$ & $1.5(1.28,1.84)$ \\
\hline
\end{tabular}

Table 3

Tolerability of Treatments' Side Effects

\begin{tabular}{|llllll|}
\hline Side effects & $\begin{array}{l}\text { Misoprostol } \\
(\mathbf{n = 9 0 )}\end{array}$ & $\begin{array}{l}\text { MVA } \\
(\mathbf{n}=\mathbf{5 8})\end{array}$ & & \\
\hline Tolerable & Severity & Freq (\%) & Freq (\%) & P -value & RR (Cl 95\%) \\
\cline { 1 - 5 } Yes & Mild & $73(81.1)$ & $45(78.6)$ & 0.677 & $1.1(0.88-1.24)$ \\
\cline { 1 - 5 } No & Moderate & $15(16.9)$ & $12(20.7)$ & - & - \\
\cline { 2 - 4 } & Severe & $2(2.2)$ & $1(1.7)$ & & \\
\hline
\end{tabular}




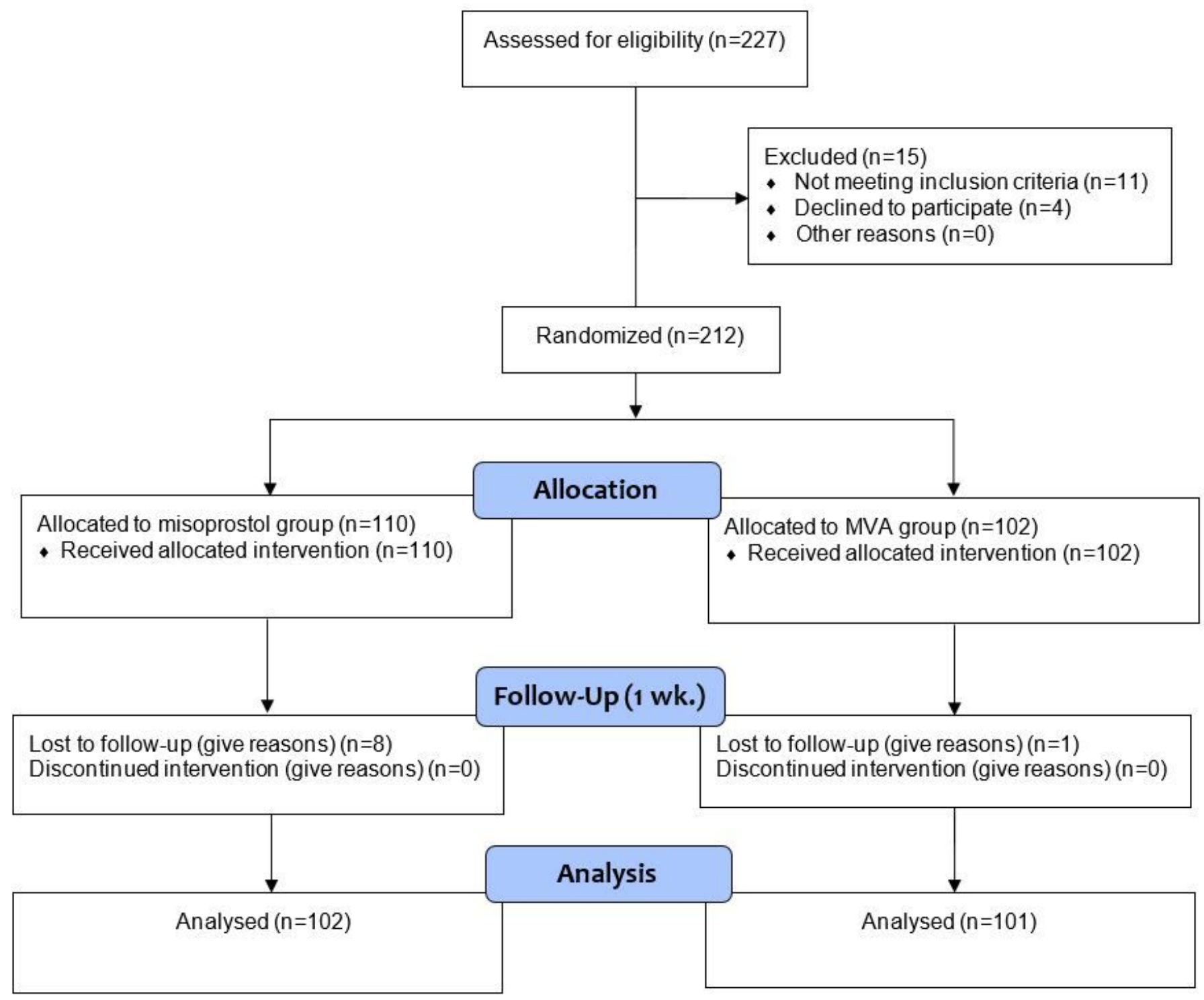

\section{Figure 1}

Study flow chart

\section{Supplementary Files}

This is a list of supplementary files associated with this preprint. Click to download.

- CONSORT2010Checklist.doc 